\title{
Role of Geometry on Architecture
}

\author{
Ar. Apoorva Ajmera \\ (B.Arch., PGP ACM, PGDUPDL, GRIHA CP) \\ Assistant Professor, Buddha Institute of Architecture and Town Planning \\ Udaipur, Rajasthan
}

\begin{abstract}
1. ABSTRACT
Man develops geometry, Geometry is the language of man, which is used in different ways The basic definition of geometry given in 'a visual dictionary of architecture" by Francis D.K.Ching states that ' a branch of mathematics that deals with the properties, measurement and relationship of points, lines and angles, end solids, deduced from the defining conditions by the means of certain assumed properties of space ". But there are several other definitions by the different use of geometry. It brings sense of continuity and structural qualities to the building. Geometry is the means, created by human beings whereby they perceive the external world and express the world within them. Geometry is the world use "common language'. Geometry is the foundation of life; it is also the material basis on which we build those symbols that represent us perfection and divine.
\end{abstract}

\section{Keywords- Geometric forms, Building forms, curves and angles of building}

\section{INTRODUCTION}

It is an overview of the basic elements, systems, and orders that constitute a work of architecture. All of these constitutes can be perceived and experienced. Some may be readily apparent while others are more obscure to our intellect and senses. Some may dominate while others play a secondary role in a building's organization. Some may convey images and meaning while others serve as qualifiers or modifiers of these messages.

In all cases, however, these elements and systems should be interrelated to form an integrated whole having a unifying or coherent structure. Architectural order is created when the organization of parts makes visible their relationships to each other and the structure as a whole. When these relationships are perceived as mutually reinforcing and contributing to the singular nature of the whole, then a conceptual order exists- an order that may well be more enduring than transient perceptual visions.

As this analysis is based on geometry, in various aspects, I have tried to find relationship with geometry and so, all the criteria are based on geometry. In various architects work, geometry is manifested in form \& shape. Geometry is evident in plan as space sequence and in details. The whole building is visualized in form of geometry and philosophies are attached to them. All these criteria are discussed in later part of this dissertation report.

\section{ELEMENTS OF GEOMETRY}

\subsection{POINT}

The fundamental element of basic designing process is a point. Point is the basis of all geometry. Point is the most basic and prime geometrical element, it is not dimension less but infinitely tiny elements. It can be said that its smallness is always relative to a respective frame. A point indicates position, and has no-length, width or depth. It is just there and is therefore static centralized and directionless, and does not occupy any area of space. It is the beginning and end of a line and is where two lines meet or intersect in the form of a center in various geometric elements.

A point marks a position in space. Conceptually, it has no length, width, or depth, and is therefore static, centralized and directionless. In architecture a point is used as an organizational element, and is the only organizational element that gives' constancy' in relationship between the point and various peripheral components. As the prime element in the vocabulary of form, a point can serve to mark:

- The two ends of a line

- The intersection of two lines

- The meeting of lines at the corner of a plane or volume

- The center of a field

3.2 LINE

As a point moves, its path becomes a line. Line is perhaps the most fundamental elements of design, since civilization began. People have been fascinated by lines. Lines fill every part of ones world, from the endless of the horizon to the delicate venis in a leaf, from the soaring to the vertical drawing or painting. The natural world abounds with lines of every description. If one studies the world around one self one finds a wealth of natural configuration in line.

Sometimes the line is also called as a distance between two points (axis). 'Line' is a vector scale which has length but no width or depth, where as a point is by nature static. A line in describing the path of a point in motion, is capable of visually expressing direction, movement and growth. It forms the border of a plane. It can serve to: Join, link, support, surround or intersect other visual elements. Describe the edges of and give shape to planes.

A form is organized as a line because of two reasons:

(a) Its breadth is extremely narrow and

(b) Its length is quite prominent.

\subsection{PLANE}

If a line moves in a direction other than the intrinsic direction, the trace of its path describes a plane. On a two dimensional surface, all flat forms that are not commonly recognized as points or lines are forms as planes. Plane has length and breadth but no depth (Third dimension). A planar form is bound by 
conceptual lines which constitute the edges of the form. The characteristics of these conceptual lines and their interrelationships determine the shape of planar form.

Vertical and horizontal are the most basic planes of spatial unit. They are the primary areas of interest in architecture. In the composition of a visual construction a plane serves to define the limits or boundaries of a volume. If architecture as a visual art deals specifically with the formation of three dimensional volumes of mass and space, then the plane should be regarded as key element in the vocabulary of architectural design. Basically the horizontal is the plane for human activities and movement. The vertical plane is the limit for each space and there by the limit for horizontal movement.

Horizontal and vertical are most basic two planes.

\subsection{VOLUME}

A plane extended in a direction other than its intrinsic direction becomes a volume. Conceptually, a volume has three dimensions: length, width and depth.

All volumes can be analyzed and are understood to consist of:

- Points or vertices where several planes come together

- Lines or edges where the planes meet

- Planes or surfaces which define two limits or boundaries of a volume

\subsection{FORM}

Form is an inclusive term that has several meanings. It may refer to an external appearance that can be recognized, as that of a chair or the human body that sits in it. It may also allude to a particular condition in which something acts or manifests itself, as when we speak of water in the form of ice or steam. In art and design, we often use the term to denote the formal structure of a work - the manner of arranging and coordinating the elements and parts of a composition so as as to produce a coherent image.

In the context of this study, form suggests reference to both internal structure and external outline and the principle that gives unity to the whole. While form often includes a sense of three-dimensional mass or volume, shape refers more specifically to the essential aspect of form that governs its appearance-the configuration or relative disposition of the lines or contours that delimit a figure or form.

\section{THE PRIME GENERATORS OF FORM: 4.1 PROPORTION}

Proportion is an ordered relationship between two comparable entities, visible or invisible. It can be manipulated and experienced by geometry; arithmetic ratios and visual perception. Certain proportion have been found to be generally satisfying to the human senses.
Proportional system is evolved out of geometrical principles. This system sets interrelationship of parts to form harmonized composition. It helps in achieving ordered relationship in design. It is a system used to relate parts in an overall composition. This system divides larger areas into parts and forms an integrated as a whole. It establishes a system of ratios to interrelated elements of different sizes and shapes within one composition. It generates an order and harmonizes elements of different sizes and shapes within one composition. It generates an order and harmonizes elements of different scales. Proportion is a means by which elements are composed to achieve the qualities of unity, balance, rhythm etc.

\subsection{ORGANIZATION}

Organization is the systematic arrangement, connection and co-ordination of parts to form a coherent totality which is not only conceivable but also perceivable and which serves a desired purpose for the vital functions and processes. Organization brings about a harmonized composition interrelating to the various parts, leading units of purpose to the whole composition. It establishes sequence by ordering and structuring relationship between solids-voids, solids-solids and voids-voids.

Organization is a combination of an order of linkage between the number of elements, which coordinate the parts for vital functions, and make a unified as whole.

\subsection{CIRCULATION}

The path taken in getting from a starting point to the destination can be termed as a "Route of Movement" A route without a destination is difficult to traverse and hence to an observer the route linking him to his destination is prime importance.

The path of our movement can be conceived as the perceptual thread that links the spaces of a building, or any series of interior or exterior spaces, together.

Since we move in Time through Sequence of Spaces, We experience a space in relation to where we've been and where we anticipate going.

\subsection{FORM \& SPACE}

'Geometry' is related to form and space. So a try has been made to inquire the depth of geometry in different forms and spaces as building. Form is inclusive term that has several meanings, which may refer to an external appearance that can be recognized. An approach to architecture is based on an individual understanding of an architect. The idea of form and space is always as the starting point and at the center while beginning any new project.

Form suggests reference to both internal structure and external outline and the principle that gives unity to whole. But most of projects, concentrated on external configuration of form. While form often includes a sense of volume, shape refers more specifically to the essential aspects of form that governs its appearance (characteristic outline). In addition to spaces (shape) and forms have visual properties of size, color, texture. Forms also have relational properties which govern the pattern and composition of elements, position, orientation, visual inertia etc. 


\section{CONSTRUCTED AND DECONSTRUCTED QUALITIES OF SPACE}

Let us consider what a vista, which is absent in one type of garden and available at all points in the other, means. A French garden is not only extremely artificial but constructed. Its flowers and trees do not appeal to ones feelings about nature but rather constitute material subordinating the entire plan. Form and material are clearly divorced and the former clearly dominates the latter. Although trees are continuously changing and being created, the consequences of such activity are not acknowledged, the trees are identified as conical a cubic forms. All plants as plants have been banished from the garden and it is only rectangles and circles that are placed and arranged on the extensive, level site paved with gravel, creating a symmetrical, geometrical pattern. There is only a completely static surface that will remain forever unchanged. To create a unified garden by compelling materials whether they may be trees or water, to take unchanging forms with no concern for diversity or generative transformations represents the complete dominance of the intellect. The result is a highly constructed space.

Making the object insubstantial confers on it a transparency and endows vision with a privileged character. Visual transparency is a quality or state allowing one to penetrate all parts of the object. It is as if the source of light and power of vision residing within the self were situated Godlike at the vertex of a cone-shaped world and the self could see into the furthest depths of the cone. No doubt, transparency according to the law of perspective approaches this conical situation.

As soon as them is a disfigurement or distortion for some reason, it must be discovered and eliminated, each time new leaves appear on plants and grow unchecked, threatening to distort conical forms and other geometrical patterns, the gardener must wield his shears with utmost seventy to correct even the slightest aberration. The planting in conical or cubic form constitutes an enclosure that confines meaning and prevent it form strring, dissolving or straying. Consequently, a French garden where the spatial order converges on one point can be said to have only one landscape. The diversity or polysyllabic of landscape and vision is to he completely ignored. That is the basic principle behind a constructed garden.

But what happens when, unlike a French garden, the garden is outcropped and the landscape is left to sway and stir as it may? What would happen if, instead of heightening perception, enlarging the cone of vision, and thereby achieving integration of the landscape through transparency at a larger scale, vision traveled from one distorted fragment to another in accordance with shifts in the point of view or the actions of the buy? Japanese garden might be the result.

As has already been pointed out, the absence of vista in characteristic of a Japanese garden. This absence of vista is a consequence of the multi-layered quality of the landscape, evident in the planting, the rock arrangement and the trees.
Rock obstructs rock and the landscape is always fragmented. Vision is not allowed in the whole of this garden either. As in the garden of Tenryuji or Nanzenji, the landscape becomes a set of overlapping and contiguous landscapes that deviate slightly from each other. Multiple landscapes coexist. As a result of Overlapping, there are always parts that are hidden. A hidden part, if one changes one's view Point, becomes patent, and what had been visible now becomes latent. This mechanism makes it difficult to apprehend the entire garden. For the viewer, the landscape at each moment certainly exists in front of his eyes, but the plan of the whole is difficult to structure. It is difficult to him to measure his creation relative to the entire garden or the distance to a given plant or rock, and without a clear order, multiple landscapes are generated as one's point of view shifts. The absence of a transcendent center or vision that can give order to space robs a Japanese garden of perspective and transforms it into un- constructed space.

However, the Japanese garden is after all an object deliberately created by man, and negative terms such as 'without order' or 'unconstructed' are surely inadequate descriptions. A Deconstructionist principle that actively promotes irregularity must be behind what appears at first glance to be without order. The multilayered, contiguous landscapes constitute parts, but these parts do not simply and willfully link themselves. Perhaps then there is something to be discovered in the way the parts are connected.

\section{EVOLUTION OF GEOMETRY FROM HISTORY TO PRESENT DAY}

Geometry is the foundation; it brings with it the noble joy of mathematics. Machinery is the result of geometry. The age in which we live is essentially a geometrical one. All the ideas are oriented in the direction of geometry. Modem art and thought, after a century of analysis, are now seeking beyond what is merely accidental. Geometry leads them to mathematical forms, a more and more geometrical attitude. geometry is used as a form of an organizational tool. Geometry is being related to different mythological theories of a form.

As man developed geometry, they attached various theories to geometrical forms. Different symbols have different meanings according to Hindu philosophy: the 'square' represents the 'earth' in conformity with the cardinal Points. It is also thought of as an abode of deity. It is mystical, absolute and a basic geometric element. It permits no changes during the process of transformation due to its religious origin. The 'Triangle' Symbolizes the Indian 'Trinity' and is the principal governing element. Based on natural form, people developed basic geometric forms.

In Islamic architecture, the 'circle' is thought as a symbol of eternity, a form without a beginning or an and. It is the most perfect and an expression of justice. Circle is the most basic and parent figure of all the geometric polygons. The 'Dome', a highly geometric element has become' an increasingly a characteristic feature of Islamic buildings. It is thought of as an 'image of heaven'. The 'square' is 
thought as the most externalized form of creation and a symbol representing the 'earth'. These various basic geometric forms are used in religious, public buildings in many ways. The courtyards Of King's tomb and queen's tomb are square in shape. The domes of both tombs are built in traditional Islamic ways. Like wise 'square' is being used as courtyards in most of the Mosques \& 'Dome' is used to represent Tombs. The development of mosque was done with combination of square and circles.

The Romans Wished to create a Symbolic form of a new Kind of systematic world order, which embraced a unified religion, a unified body of laws, and a unified civilization. This organizational spirit is revealed in their manner or grouping buildings as done in the Forums, in the organization Of business activities in common centers, in combination of three orders on the exterior of the building as in the colloseum (Tuscan Doric on first, Ionic on second and Corinthian on third and fourth); in the combination of Ionic and Corinthian to form the composite order, in the development of the multi family apartment house; various forms of recreation in baths and finally in the erection of a super temple for the principal Gods; as in the Pantheon. An organization of expansion of interior space is reflected in the great halls of the baths, Basilicas and the Partheon 'ref.2 (as written by Fleming in 1974). Romans are supposed to be main Inventors of geometry', ancient civilization.

Its geometry is based on the union of a cylinder (rotunda) and a hemisphere (dome) over a circular ground plan. The design of Pantheon displays a harmonious disposition of a circle and a rectangle. The rectangle contains two squares and a diagonal of each square is equal to the diameter of the circle. Thus, the 'latent geometry' clearly establishes a relation between the width of the portico and rotunda of the Pantheon. It unifies a celestial dome and a longitudinal axis with the vertical rising freely to the heavens through the opening zenith into a meaningful whole. The Point to be stressed was the center of the floor and not the center of the sphere. The Pantheon with its utter simplicity laid the foundation of the idea of the centralized building. The form was revitalized in different periods, each in its own manner. Even the lighting of a dome gained an almost mystic connotation in the later centuries. By creating Pantheon, Romans gave a very good example of form as geometrical organizational tool.

Greeks were able to find some of use of geometrical forms. Greek took first step to the conception of independents forms detached from any unitary word view.

In medieval and Gothic architecture, basic form was syntheses of rectangular planes with conical domical roof over it. Most of the buildings were centric forms. Besides the single space building there were examples of the extension of the centric from Into rich and complex spatial compositions, a high centric space surrounded by a ring of lower space. In S.Constanza, Rome, in 359 A.D., principle was introduced - the modestly dimensioned dome was surrounded by a barrel vaulted ambulatory.

The pure circular form was broken in S. Lorenzo, Milan, by an ambulatory and three axial chapels. The octagonal central space of $\mathrm{S}$. Vitale in Ravenna, gave rise to the sixteen sided water shell. The form was steadily becoming richer and more complex.

During the medieval ages, centric form and linear form were developed together and had been juxtaposed on each other to develop the interior spaces and the exterior forms of Turkish Mosque, Gothic and renaissance Cathedrals. The linear path passing through a centric space illustrates the crossing of the two fundamental ideas. Overlaying the cross onto the circle creates a powerful symbolic pattern, a form of mandala, where passage and destination are fused in a powerful story of faith and exhalation.

A few fundamental principles based on geometric elements were manifested by inherited spatial form in early Christian architecture. From here, the aspect of 'Third Dimension' distinguishes Byzantine architecture from Early Christian architecture. From here the basic principles remained constant with development in the third dimension. The skeletal structure and an additional tower are main character of Romanesque architecture. After Byzantine, Gothic architecture was characterized by use of pointed arch, the rational system of vaulting \& buttressing.

In renaissance architecture, geometry played a key role. The spatial geometry was determined by functions. Larger organizations were achieved by adding different geometric units retaining an identity, yet responding to the entire configuration. Functions were pre supposed by perfection form as the circle being the most perfect and divine form, as it is evident in his work.

The building that marks development of the renaissance is st. Peters in Vatican. Papal service in the sixteenth century witnessed geniuses of this time, Bramante, Vinci, Michelangelo and Raphael, in action in Rome. Bramante in 1503 was first to draw two plans for the church. He interpreted the 'pentrigion', as the central plan with four towers at the corners. The first alternative modified the Greek cross by widening the crossing, making the dome as a domical centre. This was a completely centralized church with the inner arms forming a square ambulatory around the centre. The second attempt was at general strengthening of load bearing piers and the addition of four semi-circular north axis around the four apses of the main space. The central space was crowned by a semi-spherical dome which exaggerated the meaningful centre for not only Rome but to the Christians as a whole.

In the 18 century industrialization transformed the goals and Methods of human creativity. The specific forms employed in Roman Byzantine, Romanesque, Gothic, Renaissance and baroque periods have become symbols of this epoch, with new dimensions, new character and new style.

In Italy, futurism was born of a demand for the cultural rejuvenation of the country. Putting together the similar kinds of forms created a unity. The new paintings denies the cube and wants the dynamic arabesque such as the sphere, the ellipse, the spiral and all other dynamic forms which artists can discover.

In 1919 the Bauhaus was founded on the remains of the Arts and Crafts Movement in Germany, It resulted in an unprecedented success in influencing architectural 
education all over the world. Bauhaus initiated the study of architecture by manipulating abstract shapes without any reference to building functions or the ultimate strength of materials. It was solely with a view of achieving ornamental appeal, in terms of a magnificent form'. The art of architecture turned into a kind of large-scale abstract sculpture. The art of utilizing the vocabulary of the newly fashionable cultural shapes to serve the functional and structural requirements of a specific architectural program. The extent to which severe geometrical planes were used as a form of ornamentation is evident. The comment of Hans Mayer, Director of Bauhaus from 1928 to 1929: Despite Gropies declarations that architecture has built sociology; theirs was an artificial world of forms whose limits ended in a cube whose sides were yellow, red, blue. White, grey and black within which people sat and slept on furniture like colored geometry and lived in houses like colored sculpture".

In Holland in 1917, the 'De Stijl' moment developed. The use of vertical and horizontal lines at right angles offered a balanced relationship of unequal parts. The architect's task in the movement of De Stijl, was to produce metaphorical images which foreshadow the dissolution of art into the New Harmony do, the from was not really used as organizational tool for geometry. Rietveld's famous 'Schrodler House' in Utrecht, built 1924, is a good example of De Stijl. It seems to demonstrate that De Stijl's contemporaneous manifestation on architecture could in fact be translated into actual building.

In 1918, another movement was started in France called 'Purism'. It was to purify the application of Cubist forms to machine iconography. Andee Ozenfant (188E1966) and Charles Edourd Jeanneret (18871985): published Apre's le Cubism' (after Cubism) in the same year. Cubism has degenerated into a form of elaborate decoration so the stress was on a pure form of art.

Le Corbusier developed a vocabulary of Purist aesthetics. Taking his clues, painting was developed. His idealization of platonic solids with notion of mechanization and modernity was highly influential. Either for studying to a general rationalization of building design processes, or to the regulation of surface is a charesteric feature of Avant Garde architecture. Often the general rationalization into rectilinear geometry of the plan and section resulted in surface regulation. It was usually beyond purely utilitarian needs. The works of Le Corbusier once again lead the form as the basic organizational tool for geometry.

Along with Le Corbusier and after him many architects developed architecture with different criteria of geometry. Aldo Rossi was the most fascinating figure of $\mathrm{Neo}$ Rationalism. His forms were drawn from geometry and Passed through the filter of history. It was an attempt of identification, which can occur only by appealing to consciousness and to mental image. Rossi's composition method is based on the atonal and unexpected assemblage of archetypes, which can be rearranged as form, which have flowered from memory and can be used to interpret new architectural possibilities. For him analogy is more than a tool for pervading to images with mnemonic reference and unconscious meanings.

\section{CONCLUSION}

- This study, throughout this presentation of the geometrical elements of form and space, has been concerned primarily with the visual aspects of their physical reality in architecture.

- Points, moving through space and defining lines, lines defining planes, planes defining volumes of form and space.

- Beyond these visual functions, these elements, by their relationships to one another and the nature of their organization, also communicate notions of domain and place, entry and path of movement, hierarchy and order.

- Architectural forms and spaces also have connotative meanings: associative values and symbolic content that are subject to personal and cultural interpretation, which can change with time.

- Geometry, in combining forms and space in to a single essence, not only facilitates purpose but communicates meaningful organization of elements can be achieved with conscious use of geometrical ordering principles.

- Geometry is used as a form as on ordering principles.

- Geometry makes our existence not only visible but meaningful.

- I had a myth that de-construction does not follow any geometrical principle, through the case studies of different buildings like Guggenheim museum by frank o Gehry and House projects of Eisenman.

- Through this dissertation, I have come to a conclusion that De-construction follows hidden geometry in their buildings.

- Deconstruction is relatively a new concept, so I was keen to know about it, through this dissertation I have come to a conclusion that deconstruction led to the enhancement of geometry and has taken geometry to a new level.

- If we compare constructivist and de-constructivist design we can find that only constructivist designs follows geometric principles. 


\section{BIBLIOGRAPHY/ REFERENCES}

- "ARCHITECTURE Form Space and Order" by Francis D. K. Ching.

- "Architecture for the Future" by Sheila De Vallee.

- "The Master Architects Series" Eisenman Architects.

- "New Forms in Architecture" by Phiup Jodidio, Publisher: Taschen.

- “A + D Magazines.

- "Inside Outside" Magazines.

- "The Early Work of Great Architect" by Frank Lloyed Wright.

- "Le Corbusier the Creative Search" by Geoffrey H. Baker.

- "De-Construction in Architecture" by Lavinas Chap.

\section{WEB REFERENCES}

- www.geometry.com

- www.artandarchitecture.com

- www.geometryandart.com

- www.googlesearch.com

- www.greatbuildings.com

- www.eisenmanarchitect.com

- WWW.architecturaldesign.com

- WWW.petereisenman.com

- WWW.deconstructioninarchitecture.com 